\title{
Rescued Akatsuki spacecraft delivers first results from Venus
}

\section{Streaked acidic clouds and a bow shape in the atmosphere are among its findings.}

\section{BY ELIZABETH GIBNEY}

A fter an unplanned five-year detour, Japan's Venus probe, Akatsuki, has come back to life with a bang. On 4-8 April, the Japan Aerospace Exploration Agency (JAXA) presented the first scientific results from the spacecraft since it was rescued from an errant orbit around the Sun and rerouted to circle Venus, four months ago. These include a detailed shot of streaked, acidic clouds and a mysterious moving 'bow' shape in the planet's atmosphere.

Despite the probe's tumble around the Solar System, its instruments are working "almost perfectly", Akatsuki project manager Masato Nakamura, a planetary scientist at JAXA's Institute of Space and Astronautical Science in Sagamihara, Japan, announced at the International Venus Conference in Oxford, UK. And if another small manoeuvre in two years' time is successful, he said, the spacecraft might avoid Venus's solar-power-draining shadow, and so be able to orbit the planet for five years, rather than the two it was initially assigned.

Akatsuki, which means 'dawn' in Japanese, launched in 2010 and was supposed to enter into orbit around Venus later that year to study the planet's thick atmosphere. The mission would include looking for signs of active volcanos and other geology. But upon entry, a fault in a valve caused the probe's main engine to blow, and the craft instead entered an orbit around the Sun. As Akatsuki passed near Venus in December, JAXA engineers managed to salvage the mission by instructing the craft's much smaller, secondary thrusters to push it into a looping elliptical orbit around the planet. The results presented in Oxford were captured from this vantage point with a suite of five cameras that capture light ranging from infrared to ultraviolet.

A highly detailed shot of dense layers within Venus's sulfuric acid clouds elicited applause from the audience. The highest-quality infrared image of this view of Venus, it suggests that the processes that underlie cloud formation might be more complicated than thought, project scientist Takeshi Imamura told attendees.

And the team expects still better results to come. The image was taken from 100,000 kilometres away - more than 10 times the probe's distance at its closest pass of Venus. "We will achieve better spatial resolution still," said Takehiko Satoh, principal investigator for the

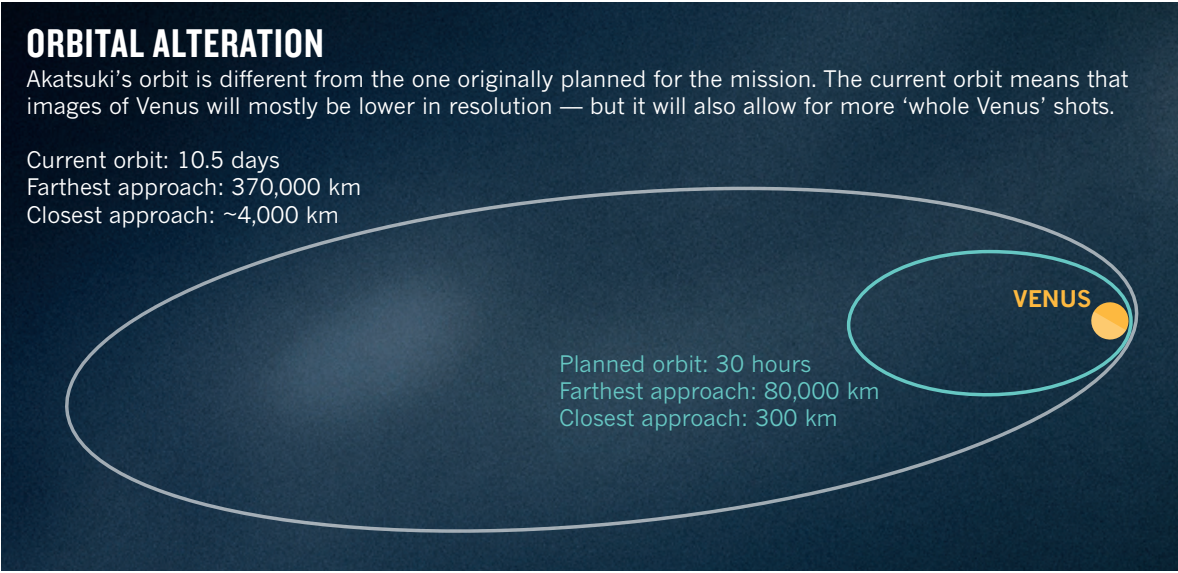

probe's 2-micrometre infrared camera, IR2, which took the image. "We promise to give a fantastic data set to the research community for years."

The bow shape, which was seen in thermal images taken using a long-wave infrared (LIR) camera, provided some intrigue. The moving
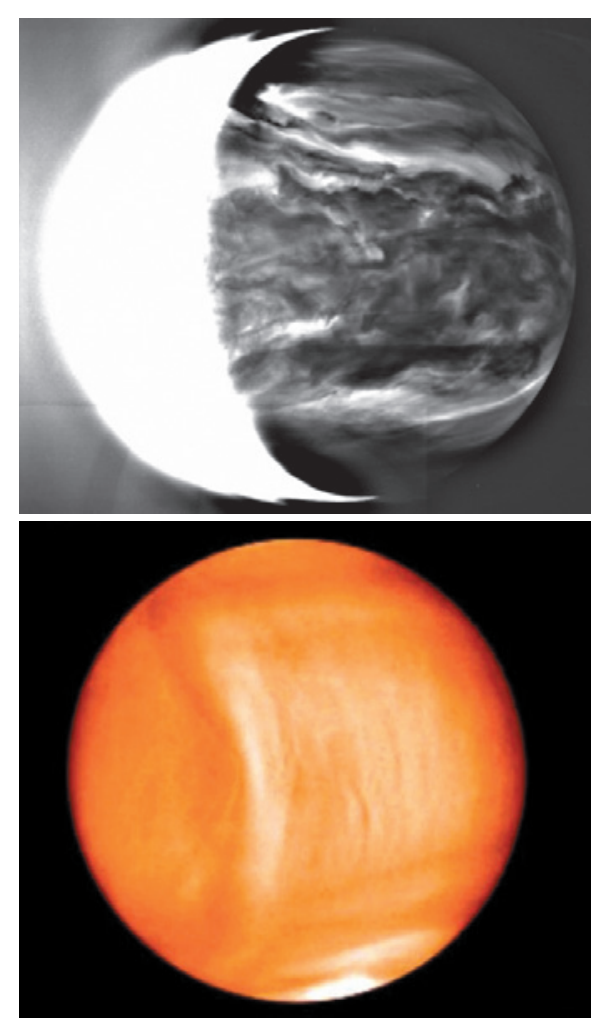

Streaked clouds and a mysterious 'bow' shape. cloud formation, which swept from pole to pole across the planet for days, seemed to rotate with Venus's surface, rather than with its much quicker-moving atmosphere.

The motion suggests that the front could be linked to features on the ground, said Makoto Taguchi, who leads the LIR camera. Others at the conference were at a loss as to what may have caused it. "It's certainly mysterious," says planetary scientist Suzanne Smrekar of NASA's Jet Propulsion Laboratory in Pasadena, California.

Akatsuki's success has cheered researchers, especially because it is now the only working probe deployed at Venus. "The mood is very good," says Colin Wilson, a planetary scientist at the University of Oxford, UK. Akatsuki's orbit - which was tweaked slightly on 4 April to give the probe the best chance of lasting for years to come, as well as to provide a good scientific vantage point - will allow it to survey Venus's equator as originally planned. The resulting images will complement surveys of the planet's poles from the European Space Agency's Venus Express orbiter, which ended its mission in 2014.

But Akatsuki's new lease of life comes with compromises, too. Its current 10.5-day operational orbit takes it almost 5 times as far from Venus at its most distant point than its original intended orbit (see 'Orbital alteration'). Except for those taken during the short period when the probe sweeps close to the planet, images will be lower in resolution than planned. This means that studies that require detail, such as spotting flashes of lightning, will take longer But the team said that it plans to make the best of the probe's wide orbit to take whole-Venus 
images that track large-scale features over time.

The mission has also not shrugged off all consequences of its long and unexpected cruise around the Sun. One camera malfunctioned in January, probably because of gradual contamination of a helium coolant with water vapour over the years, said Satoh. Engineers have now fixed the problem by warming the coolant to disperse the vapour, but it took a while. "We had a painful blank of about a month," says Satoh.

Planetary scientists outside of JAXA will have to wait a year from acquisition to access the data, but they are nonetheless excited by the probe's initial success. Two Venus-based projects are among five proposals shortlisted by NASA for possible launch in the early 2020 s. The agency is expected to decide by the end of December, and Venus missions could get a boost from Akatsuki's success - especially if the orbiter finds intriguing features that require follow up, says Smrekar, who leads one of the Venus proposals that NASA is considering, the proposed VERITAS radar orbiter. "If they're able to see new volcanism, for example, it definitely makes the case for going back to explore more fully," she says. - SEE EDITORIAL P.148

US rethinks crop regulation

Committee begins study to guide oversight of gene-edited organisms.

\section{BY HEIDI LEDFORD}

$\mathrm{T}$ The industry that has blanketed more than 181 million hectares of the world's farmland with genetically modified (GM) crops is in the middle of a sea change. Improved techniques for altering crop genomes are already bringing a new generation of plant varieties to the market and around the world, regulators are playing catch-up.

"A few brave countries have already made statements," says Piet van der Meer, a biologist and lawyer at Ghent University in Belgium. "But most are struggling with it."

On 18 April, the US National Academies of Sciences, Engineering and Medicine will begin its first meeting of a committee charged with ending the struggle. The committee, which is sponsored by the US Department of Agriculture (USDA) and two other agencies, has been asked to predict what advances will be made in biotechnology products over the next $5-10$ years. It is scheduled to report by the end of the year on the steps that regulators need to take to prepare themselves. The result could inform an ongoing USDA effort to re-assess its

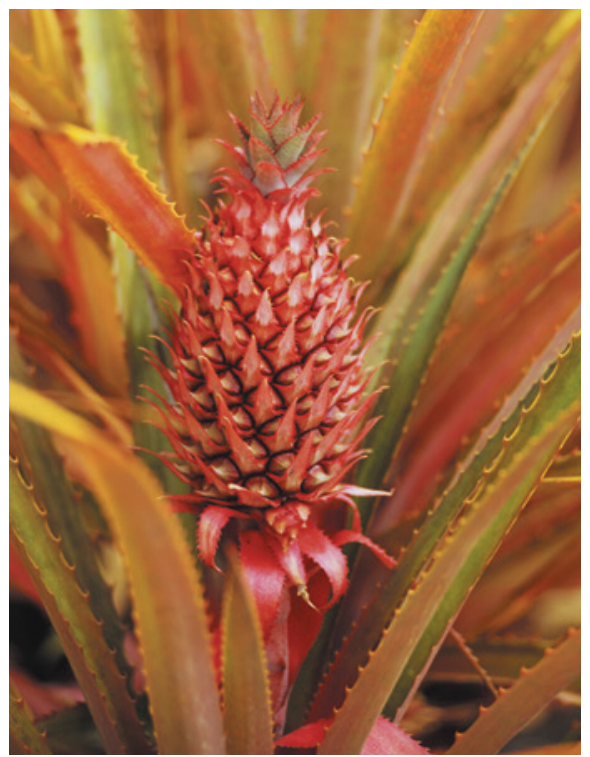

The genetically engineered pink pineapple can be imported into the United States.

process for evaluating engineered crops.

Researchers around the world are watching closely (see 'Global governance'). “Crops travel around the globe," says René Custers, manager of regulatory and responsible research at VIB, a life-sciences research institute in Ghent. "It is important to see what is happening in the rest of the world."

\section{RIPE FOR CHANGE}

Many feel that regulations in the United States, which grows more GM crops than any other country, are particularly ripe for change. The USDA itself has acknowledged that it might be over-regulating some crops if they have traits that have already been scrutinized. Also, it uses its authority to restrict the release of 'plant pests' as a way to regulate GM crops - an approach that applied widely in the 1980 s, when crops were often created using genetic elements from plant viruses or bacteria.

But researchers have since developed tools that do not rely on these components. Over the past five years, the USDA has determined that about 30 types of GM plant - from soya beans whose oil has a longer shelf life, to pineapples with rose-coloured flesh - do not fall under its regulatory rubric. Some were made using gene-editing techniques.

"One of the things that has to happen is to plug

\section{GLOBAL GOVERNANCE}

\section{Nations take a variety of approaches to regulating gene-edited products.}

Like the United States, many countries are grappling with how to regulate crops that have been engineered using gene editing and other 'new breeding techniques' (NBTs).

Argentina In 2015, regulators decided that crops made using NBTs would be reviewed on a case-by-case basis.

Australia A 2013 workshop convened by the Food Standards of Australia and New Zealand recommended that NBT crops bearing simple deletions need not be considered GM food, but those with inserted genes should.

European Union The European Commission is expected this year to produce long-delayed advice on applying existing regulations to NBT crops.

Japan No official stance on gene-edited technologies, the products of which do not fall under the country's definition of a 'transgenic' crop.

Canada Decisions are made on the basis of whether the crops have new traits, irrespective of how the traits are produced.

New Zealand The Environmental Protection Authority determined that some crops made through NBTs would not be regulated, but the high court overruled the decision in 2014. H.L. 